\title{
ANÁLISE DISCURSIVA DOS RESULTADOS DO PISA-BRASIL NO SITE DO INEP
}

\section{Discursive Analysis of PISA-BRAZIL results on the INEP website}

\author{
Ketulyn Ferreira Fernandes. ${ }^{1}$ \\ UNIVERSIDADE SÃO FRANCISCO
}

Márcia Aparecida Amador Mascia ${ }^{2}$ UNIVERSIDADE SÃO FRANCISCO

\begin{abstract}
Resumo: A partir do escopo teórico discursivo, este artigo pretendeu analisar o PISA-Brasil com enfoque nos resultados pertencentes ao ano de 2015. O PISA (Programme for International Student Assessment) realiza provas a cada 3 anos com estudantes de 15 anos de idade, por ser esta a idade do último ano de escolaridade obrigatória, coincidindo com a maioria dos países participantes dentre os mais de 100 países membros e não-membros da OCDE (Organização para Cooperação e Desenvolvimento Econômico). Em nível mundial, o PISA é coordenado pela OCDE e em nível brasileiro pelo INEP (Instituto Nacional de Estudos e Pesquisas Educacionais Anísio Teixeira), responsável pela função de elaboração e aplicação da prova no Brasil, possuindo cada país seu órgão próprio. Levando em conta o contexto apresentado acima, o objetivo deste artigo é levantar os sentidos sobre os resultados do PISA dispostos no site do INEP, e como eles constroem novos regimes de verdade em educação. Pretende-se compreender as discursividades contemporâneas em relação às avaliações externas e como elas afetam a educação, primordialmente, a educação brasileira. Do ponto de vista do referencial teórico, pautamo-nos na análise do discurso em linha francesa, que considera o sujeito como efeito do discurso e o discurso como situado socio-ideológicohistoricamente, sendo que os dizeres não nascem nos sujeitos, mas nas formações discursivas dentro das quais o sujeito se situa. Os resultados da análise apontam que as políticas públicas devem investir mais nas condições socioeconômicas gerais de um país de modo a diminuir as desigualdades sociais, ao invés de só focar na educação. Países com maiores desempenhos são países que investem em equidade social.
\end{abstract}

Palavras-chave: PISA; Avaliações externas; Educação; Discurso.

Abstract: From the theoretical discursive scope, this article intended to analyze PISA-Brasil with a focus on the results referring to the year 2015. PISA (Program for International Student Assessment) conducts tests every 3 years with 15 -year-old students, considered as the age of the last year of compulsory education, coinciding with most of the participating countries out of more than 100 member countries and nonmembers of the OECD (Organization for Economic Cooperation and Development). At the global level, PISA is coordinated by the OECD and at the Brazilian level by INEP (National Institute of Educational Studies and Research Anísio Teixeira), responsible for the task of preparing and applying the test in Brazil, with each country having its own department. Taking into account the context presented above, the purpose of this article is to raise the senses about the PISA results displayed on the INEP website, and how they build new systems of truth in education. It is intended to understand contemporary discourse in relation to external evaluations and how they affect education, primarily, Brazilian education. From the point of view of the theoretical framework, we are guided by the French Discourse Analysis, which considers the subject as the effect of the discourse and the discourse as situated socio-ideological-historically, from which the sayings are not born in the subjects but in the discursive formations. within which the subject is located. The results of the analysis show that public policies should invest more in the general socioeconomic conditions of a country in order to reduce social inequalities, instead of focusing only on education. Top performing countries are countries that invest in social equity.

Keywords: PISA; External evaluation; Education; Discourse.

\footnotetext{
${ }^{1}$ Graduanda em Pedagogia, pela Universidade São Francisco - Estado de São Paulo. Bolsista de Iniciação Científica CNPq.

2 Pós-Doutora em Educação pela Universidade de Wisconsin-Madison. Professora do Programa de Pós-Graduação em Educação da Universidade São Francisco - Estado de São Paulo.
} 


\section{INTRODUÇÃO}

O PISA (Programa Internacional de Avaliação de Estudantes) vem se afirmando, ao longo deste novo milênio, como um dos principais meios de ação da OCDE (Organização para Cooperação e Desenvolvimento Econômico) no campo educativo, de modo a oferecer um levantamento, para aqueles países que dele participam, de dados sobre os conhecimentos e as competências dos seus alunos e, consequentemente, sobre o desempenho dos seus sistemas de ensino. Cada país tem um órgão responsável por cuidar das avaliações, aqui no Brasil é o INEP (Instituto nacional de Estudos e Pesquisas Educacionais Anísio Teixeira).

Os dados levantados pelo PISA se dão pela aplicação de uma prova realizada por estudantes de 15 anos de idade, compreendida nas áreas de: leitura, matemática e ciências. E a partir desses indicadores de cada país participante, é possível subsidiar a melhoria nas políticas públicas da educação. Segundo o site, mais do que apenas julgar os rankings de cada país, esta classificação ajudaria a tornar mais efetiva a formação dos jovens para a vida futura e para a participação ativa na sociedade contemporânea, o que esta pesquisa pretendeu problematizar.

Levando em conta o contexto apresentado acima, o objetivo deste artigo é levantar os sentidos sobre os resultados do PISA dispostos no site do INEP ${ }^{3}$, e como eles constroem novos regimes de verdade em educação. Pretende-se compreender as discursividades contemporâneas em relação às avaliações externas e como elas afetam a educação, primordialmente, a educação brasileira.

Trata-se de uma pesquisa qualitativa e interpretativista, e contou com um objeto de pesquisa de base documental, neste caso, documentos encontrados no site do INEP sobre os resultados do PISA-Brasil referente à prova aplicada em 2015. Tomamos como corpus o PISA in focus que apresenta comentários comparativos da prova e do nível socioeconômico entre os países membros e não-membros da OCDE, que foi por nós analisado discursivamente.

A seguir, apresentamos o referencial teórico, seguido do contexto do PISA, a análise de excertos e as conclusões.

\section{REFERENCIAL TEÓRICO: A ANÁLISE DO DISCURSO}

Para a Análise do Discurso de linha francesa, dois conceitos são basilares: Discurso e sujeito. O termo discurso é comumente entendido como textos com palavras mais rebuscadas e pronunciamentos políticos, mas para a Análise do Discurso, o discurso transcende o meramente linguístico e se encontra no social de natureza não linguística. Assim, o discurso é um objeto histórico e ideológico, constitui-se da

\footnotetext{
3 INEP- Instituto Nacional de estudos e Pesquisas Educacionais Anísio Teixeira. Disponível em: http://portal.inep.gov.br/web/guest/pisa. Acesso em 26 de Novembro de 2018.
} 
dispersão de acontecimentos e práticas que são compreendidas com a análise de lugares e sujeitos sociais, históricos, culturais e ideológicos, marcados no momento de sua produção.

Desse modo, a análise discursiva envolve inter-relações teóricas, contextos e situações marcados principalmente pelas posições relativas ao poder, e estas posições revelam o posicionamento de quem escreve ou fala o discurso.

O sujeito na Análise do discurso não é um indivíduo falante e homogêneo, e sim sujeito heterogêneo, constituído de vários discursos, ideologias e diferentes vozes, não é, portanto, nem individual nem homogêneo. Segundo Fernandes (2008).4, o sujeito deve ser considerado sempre como um ser social, que não tem existência individual, mas situa-se em um espaço social e ideológico, e a voz desse sujeito revela o lugar social que ocupa e o conjunto de outras vozes que lhe constituem.

O sujeito é entendido como efeitos de sentido do discurso, sendo ambos (discurso e sujeito) atravessados pela ideologia e pelo inconsciente. É importante ressaltar que o discurso transcende o meramente linguístico e deriva do histórico-social. O papel da AD, segundo Pêcheux e Gadet (2004)5, consiste em "conceber o não dito, o efeito in absentia da associação, em seu primado teórico sobre a "presença" do dizer e do sintagma; o não-dito é constituinte do dizer, porque o todo da língua só existe sob a forma não finita do "não-tudo", efeito da alíngua...” (PÊCHEUX e GADET, 2004, p.58).

Assim, a análise se dá no entrecruzamento do acontecimento e da estrutura e na tensão entre descrição e interpretação, região de equívoco, de elipse, de falta, próprios da língua estruturada pela ordem do simbólico, instaurado este pela ideologia e pelo inconsciente (PÊCHEUX, 2002) ${ }^{6}$.

Como dissemos, discurso e sujeito estão atrelados e só há sentido pela identificação do sujeito com as formações discursivas que o constituem. Ao se filiar a uma determinada formação discursiva, o sujeito se revela, isto é, ao constituir o discurso ele se constitui pelo discurso. Importante destacar que o discurso, enquanto objeto teórico e analítico, só pode ser apreendido a partir da análise de sua condição de produção, ou seja, de seu processo de produção, não de seus produtos. Assim, analisar o discurso enunciado pelas políticas educacionais, como o PISA, implica em compreender a posição sujeito dos enunciadores, suas representações e imagens do que é educação, do que são políticas educacionais e assim por diante.

Como descreve Fernandes (2008, p.84), "Diante do objeto discursivo tomado para análise, é necessário sair da materialidade linguística para compreendê-la em sua exterioridade, no social, espaço em que o linguístico, o histórico e o ideológico coexistem em uma relação de implicância."

A seguir, apresentamos um breve histórico do PISA.

\footnotetext{
${ }^{4}$ FERNANDES, Cleudemar Alves. Análise do discurso: reflexões introdutórias. São Carlos: $2^{\mathrm{a}}$ ed, Editora Claraluz, 2008.

${ }^{5}$ PÊCHEUX, M. e GADET, F. A Língua Inatingível. Campinas: Pontes, 2004.

${ }^{6}$ PÊCHEUX, M. O Discurso: estrutura ou acontecimento. Trad. Eni P. Orlandi. $3^{a}$ edição - Campinas: Ed. Pontes, 2002.
} 


\section{O PISA}

O PISA7 , (Programme for International Student Assessment), Programa Internacional de Avaliação de Estudantes, realiza a cada 3 anos avaliações com estudantes de 15 anos de idade, estudantes que estão perto ou no término da escolaridade básica obrigatória. No ano de 2000, foram iniciadas essas avaliações, compreendendo 3 áreas do conhecimento, leitura, matemática e ciências, e a cada ano sendo uma destas 3 áreas mais analisadas e foco de discussões e seminários em cada país participante.

Em 2015 foram acrescentadas as competências financeira e de resolução de problemas para serem avaliadas também. Além de observar as competências, o PISA coleta informações para a elaboração de indicadores demográficos, socioeconômicos e educacionais, estes resultados e análises estão sendo usados como instrumentos de trabalho na definição e refinamento de políticas educativas, assim sendo mais efetivo a formação dos jovens para a vida futura e para a participação ativa na sociedade.

O PISA tomou-se referência na avaliação em larga escala no contexto mundial, e desde então o número de países e economias participantes tem aumentado. Em 2015, participaram do PISA 35 países membros da OCDE e 35 países parceiros.

Participam grandes grupos de países no PISA, o Grupo Ibero-americano composto por Argentina, Chile, Colômbia, Espanha, México, Portugal, Uruguai Panamá, Peru, Brasil e Costa Rica. E o Sul-americano Argentina, Brasil, Peru, Uruguai, Chile, Colômbia e Venezuela. Nem todos os países participaram de todas as edições do PISA, mas o Brasil participa de todas as edições desde a primeira em 2000 e destes 2 grandes grupos.

Na perspectiva do Brasil, desde o início, em 2000 e 2003 o foco das análises eram as regiões do país, a localização das escolas e as dependências administrativas, em 2006 também foi acrescentado o IDH (Índice de Desenvolvimento Humano). Já em 2012 surgiu a novidade que a prova poderia ser aplicada eletronicamente, seguida de uma boa notícia porque foi o único país que cresceu seus índices de desempenho em matemática. Em 2015, 964 escolas foram contempladas com a aplicação da prova, agora 100\% eletrônica.

Em 2015, o gasto acumulado por aluno entre 6 e 15 anos de idade no Brasil equivaleu a 42\% da média do gasto por aluno em países da OCDE, os aumentos no investimento em educação precisam agora ser convertidos em melhores resultados na aprendizagem dos alunos, já que esta proporção era de $32 \%$ em 2012. Entretanto, outros países do grupo ibero-americano, como a Colômbia, México e Uruguai obtiveram resultados melhores em 2015 comparados ao Brasil, embora tenham um custo médio por aluno inferior.

O desafio maior passa a ser como administrar os recursos e aproveitar da melhor maneira para que o desempenho e rendimento dos alunos aumente e seja proveitoso tanto para o conhecimento adquirido quanto para a aplicação deste na sociedade. $O$ fato de o Brasil ter expandido o acesso escolar a novas parcelas da população de jovens sem declínios no desempenho médio dos alunos já é um desenvolvimento bastante positivo.

${ }^{7}$ O levantamento sobre o PISA foi feito com base no site do INEP: http://portal.inep.gov.br/web/guest/pisa 
A seguir, serão apresentados alguns excertos escolhidos da série de publicações PISA in focus, uma série de artigos abordando comparações de todos os países. Entre essas comparações encontramos a relação de desempenho e nível socioeconômico, horas dedicadas ao estudo, a relação de gêneros e as áreas do conhecimento, a valorização dos professores, escola pública vs. privada, entre outros, dos quais tiramos excertos para fazermos análises de acordo com a Análise do Discurso.

\section{ANÁLISE DISCURSIVA}

Foram levantadas mais de 100 páginas referentes aos resultados do PISA-2015, em relação ao Pisa em Foco, uma série de publicações da OCDE que traz textos curtos, baseados em dados provenientes das aplicações do PISA, sendo escolhidos alguns excertos para a análise. O conteúdo do PISA em Foco aborda reflexões sobre educação pré-escolar, melhoramento de desempenho, disciplina escolar e absenteísmo, abrindo espaço para discussões de relevância na educação. De um modo geral, os excertos escolhidos para análise tematizam a relação entre os resultados do PISA e as questões sociais.

A seguir apresentamos o PISA em Foco número 1, que tem como proposta responder a seguinte questão: "Frequentar a educação pré-escolar traduz-se em melhores resultados na escola?"

\section{Os sistemas escolares em que há maior equidade e melhores desempenhos são aqueles em que há também menor desigualdade socioeconômica no acesso à educação pré-escolar. \\ Para concluir: Ampliar o acesso à educação pré-escolar pode melhorar tanto desempenho geral como a equidade, redu₹indo disparidades socioeconômicas entre os estudantes, se essa cobertura ampliada não comprometer a qualidade do serviço oferecido.}

De acordo com o excerto acima, quanto menor a desigualdade socioeconômica e, portanto, maior acesso à educação pré-escolar, melhor o desempenho do país em relação ao PISA. Contudo, o trecho alerta para que, ao ampliar o acesso à educação pré-escolar, as políticas públicas precisam se certificar de que a qualidade da educação deve ser mantida.

Do ponto de vista da materialidade linguística, essa relação entre ampliação da oferta e manutenção da qualidade aparece relacionada aos termos "maior equidade", "melhores desempenhos" e "menor desigualdade socioeconômica". Pode-se entende equidade como critério de justiça, de modo a adaptar, ajustar para que todos tenham os mesmos direitos, a mesma justiça. Entende-se equidade, no caso de políticas públicas aplicadas à educação, em oferecer mais para quem tem menos, ou seja, as políticas públicas precisam detectar as regiões, cidades, escolas mais desfavorecidas e oferecer uma melhor qualidade de formação dos professores, de condições salariais decentes, condições de permanência do aluno na escola, já que no Brasil o acesso é quase 100\%, porém, ocorre uma evasão muito grande desde os primeiros anos.

Um dos reflexos de aprendizagem é encontrado no ambiente familiar do aluno, questionamento feito no PISA em Foco 10: "O que os pais podem fazer para ajudar os filhos a terem sucesso na escola?” 
A vantagem no desempenho dos estudantes cujos pais liam para eles em seus anos iniciais de escolarização é evidente, não importando o nível socioeconômico da família.

Os dados revelam que os hábitos de leitura da criança devem ser estimulados desde quando o aluno ainda é muito pequeno. Ler para uma criança é ensiná-la sobre a importância da leitura, já que esta é presente no dia-a-dia dos indivíduos na sociedade. E não importa o nível socioeconômico da família, mesmo que for baixo, se este estímulo ocorrer desde cedo, ela irá ter facilidade nesse aspecto de aprendizagem na escola. Ainda sobre o nível socioeconômico, mas dessa vez falando sobre a educação mundial, o PISA em Foco 13 questiona: "Pode o dinheiro comprar um bom desempenho no PISA? “

Maior renda nacional ou maior gasto em educação não garantem melhor desempenho dos alunos.

Entre os paises de maior renda, a quantia gasta em educação é menos importante do que como os recursos são utilizados.

Os sistemas de ensino bem-sucedidos, nas economias de maior renda, tendem a priorizar a qualidade dos professores em vez do tamanho das turmas.

Para concluir: Somente o dinheiro não compra um bom sistema educacional. Os países de melhor desempenho no PISA são aqueles que acreditam - e agem de acordo com essa crença - que todas as crianças são capazes de obter sucesso escolar. Entre as economias mais ricas, aquelas que priorizam a qualidade dos professores ao invés de turmas menores tendem a obter melhor desempenho. Quando se trata de dinheiro e educação, a questão não é quanto? mas sim para quê?

O trecho acima nos revela que investir altos valores em educação não garante bons resultados, o importante é como o dinheiro é aplicado, de modo a oferecer uma educação de qualidade para todos, ou seja, “acreditar que todas as crianças sejam capazes de obter bons resultados”. Nesse caso, há diversos fatores responsáveis por fazer com que o desempenho dos estudantes aumentem. Um deles é o aluno saber e ter consciência da importância que a escola tem, o quanto se dedica às aulas e o interesse por aproveitar o máximo que puder do tempo em que está lá. Muitos alunos acabam abandonando a escola, às vezes por não terem como ir, ou até mesmo por ter que trabalhar, devido às baixas condições socioeconômicas de sua família. O mesmo pode-se dizer do Brasil. Outra questão é o caso da qualidade dos professores, eles são peças fundamentais para garantir a qualidade e o aproveitamento de aprendizagem. Também, é apresentado que o número de alunos em sala de sala não é fator tão importante, o que vale é a qualidade do ensino. Dois pontos são importantes acima: a qualidade da formação do professor e o bom uso do investimento em Educação.

Ao se tratar da localidade das escolas, o PISA em foco 28 questiona: "O que faz com que as escolas urbanas sejam diferentes?”

Ao contrário do que imagina a sabedoria convencional a respeito de escolas em cidades grandes, o PIS A observou que os estudantes nessas escolas geralmente possuem um desempenho melhor do que aqueles que frequentam escolas em zonas não urbanas. Além de a diferença de desempenho estar relacionada à condição socioeconômica dos estudantes, ela também está associada a algumas das características que distinguem as escolas urbanas, tais como poder contar com mais e melhores recursos, maior autonomia no modo em que alocam recursos e uma provisão adequada de professores. 
Segundo o trecho acima, as escolas urbanas tendem a se saírem melhor nos desempenhos do PISA, isso porque possuem uma estrutura mais adequada, e melhor para seus alunos, além de maior autonomia para direcionar seus recursos e uma maior qualificação dos professores. Talvez o que torna isso mais fácil seja a localização, já que as escolas mais distantes tenham um difícil acesso ao saber socialmente reconhecido.

Contudo, pesquisas como a de Santos, Vilalva e Ferreira (2018). ${ }^{8}$ têm questionando os resultados das avaliações em larga escala. Os autores analisaram duas escolas no município de Corumbá - MS e verificaram que não existem diferenças significativas entre a escola bem avaliada e a mal avaliada. O que ocorre, na verdade, é que a que se saiu bem nas avaliações externas é aquela cujo corpo docente literalmente prepara os alunos para as avaliações, "sem questionar a validade e o que de fato representam para a formação humana e escolar dos alunos" (SANTOS, VILALVA e FERREIRA, 2018, p. 312). Nesses termos, "a escola passar a incorporar programas de treinamento para as avaliações realizadas" (SANTOS, VILALVA e FERREIRA, 2018, p. 312).

Em relação à disciplina, o PISA questiona: "Os estudantes alcançam melhores desempenhos nas escolas em que há disciplina em sala de aula?”

\section{Escolas com maior população de estudantes socioeconomicamente favorecidos tendem a ter um clima disciplinar melhor. \\ Um clima disciplinarpositivo pode ajudar a atenuar o impacto que a condição socioeconômica dos estudantes exerce sobre seus desempenhos. \\ Para concluir: Um clima disciplinar propicio à aprendizagem não é apenas positivamente relacionado com o desempenho dos estudantes, mas, como os resultados do PIS A sugerem, também pode reduzir o impacto do contexto socioeconômico dos estudantes sobre o desempenho.}

Mais uma vez vemos a influência do fator socioeconômico, presente no contexto dos resultados e desempenhos do PISA. Um ambiente onde os alunos vivem confortáveis economicamente tende a refletir bons resultados no PISA, o tão falado "sucesso escolar. Contudo, segundo o excerto, mesmo em condições socioeconômicas desfavorecidas, havendo disciplina, os alunos tendem a se sair bem na prova do PISA. Disciplina, neste excerto, significa "clima disciplinar propício à aprendizagem", condições adequadas, não disciplina por si só, sem que tenha um objetivo educacional.

Além da população nativa do país, sempre contamos com os estudantes imigrantes para a complementação dos resultados no PISA, e uma análise do PISA em foco 33 responde esta questão: "O que os estudantes imigrantes nos mostram sobre a qualidade dos sistemas educacionais?”

\footnotetext{
A diferença entre o desempenho dos estudantes imigrantes e dos não imigrantes com o mesmo padrão socioeconômico é menor nos sistemas com grandes populações de imigrantes e nos quais as desigualdades socioeconômicas são as mesmas tanto para os estudantes imigrantes como para os demais.
}

\footnotetext{
${ }^{8}$ SANTOS, F. A. dos; VILALVA, D. M. e FERREIRA, F. da S. As implicações das avaliações em larga escala sobre a escola e o trabalho pedagógico. In: LIBÂNEO, José Carlos e FREITAS, Raquel A. Marra da Madeira. Políticas educacionais neoliberais e escola pública: uma qualidade restrita de educação escolar. Editora espaço acadêmico, Goiânia, 2018.
} 
Para concluir: $O$ fato de que estudantes imigrantes do mesmo país de origem, com a mesma bagagem cultural e com o mesmo status socioeconômico apresentem desempenhos tão diferentes nos diversos países que os acolheram indica que as politicas educacionais e sociais podem ter um impacto não apenas no desempenho em leitura desses estudantes, mas também na forma como eles são preparados para tirar o máximo proveito das oportunidades que o país anfitrião lhes oferece.

Quando os estudantes imigrantes possuem o mesmo nível socioeconômico que os estudantes "nativos", estes tendem a não possuir o mesmo nível de desempenho no PISA, seja alto ou baixo desempenho. As políticas educacionais do país que recebem este imigrante são importantes para que esses alunos se sintam acolhidos e consigam se integrar, acompanhar as aulas, para garantir os bons desempenhos destes que agora fazem parte do país, por isso, é necessária essa garantia de ensino. Isso se explica porque a prova é escrita na língua do país em que está sendo aplicada o que pode afetar a compreensão daqueles que ainda não são fluentes na língua do país anfitrião.

\section{CONSIDERAÇÕES FINAIS}

As considerações finais desta pesquisa em relação às análises do PISA-Brasil para se pensar em políticas públicas da educação a partir do levantamento do PISA in focus apontam para os seguintes aspectos: 1) que não é necessário o país ser economicamente o mais rico, no topo do ranking mundial, basta aplicar corretamente os recursos e verbas destinadas à educação. 2) As políticas públicas devem investir mais nas condições socioeconômicas gerais de um país de modo a diminuir as desigualdades sociais, ao invés de só focar na educação. 3) Países com maiores desempenhos são países que investem em equidade social. 4) Em relação à qualidade da educação, o aluno é cobrado por seu desempenho, deve mostrar conhecimento, mas se não houver qualidade na educação, no ensino, não haverá aprendizagem. 5) Direito à educação não é somente a frequência escolar, é também a aprendizagem, conteúdos relevantes. 6) É necessário acompanhar as etapas da escolaridade. 7) Equidade e resiliência devem ser pensadas e executadas pelas políticas públicas, ou seja, oferecer mais para quem tem menos. 8) Quando necessário, intervir para os melhores resultados, não somente resultados na classificação comparada a outros países, mas também resultados na sociedade, os estudantes devem atuar como bons cidadãos. Concluímos que os excertos mostram uma relação intrínseca, entre a Educação, seus resultados e as questões socioeconômicas.

Segundo Bautheney (2014). ${ }^{9}$, as avaliações padronizadas deveriam analisar a exclusão escolar proveniente das políticas públicas, não apenas medir o desenvolvimento dos estudantes e instituições escolares, é necessário também que haja a implantação de programas que assegurem a equidade e qualidade na educação. Como destaca Bautheney (2014, p. 141), há “uma ênfase no desempenho dos alunos nas provas (em que as notas seriam a expressão de certa capacidade cognitiva) e uma tendência à responsabilização

\footnotetext{
${ }^{9}$ BAUTHENEY, Katia Cristina Silva Forli. Incongruências no discurso sobre qualidade da educação brasileira. Est. Aval. Educ., São Paulo. v. 25, n.57, p. 138-162, jan./abr. 2014.
} 
deles (e de suas famílias, suas escolas, seus professores) pelos maus resultados". A qualidade na educação passou a ser responsabilidade individual, descaracterizando assim, um direito social garantido na constituição, tanto por parte das instituições públicas, como particulares. Qualidade significa um bom resultado onde a maior parte dos alunos mostram que está ocorrendo com notas significativas nestas avaliações padrão, e o Estado não deve, e nem pode, responsabilizar os estudantes pelos maus resultados.

Terminamos esta pesquisa com a seguinte conclusão, se compararmos o Brasil com os países membros da OCDE, como Singapura, Finlândia, dentre os primeiros colocados nos últimos resultados do PISA, as políticas públicas educacionais brasileiras estão caminhando no sentido oposto de proporcionar a equidade conforme atesta o estudo realizado nesta pesquisa.

\section{REFERÊNCIAS}

BAUTHENEY, Katia Cristina Silva Forli. Incongruências no discurso sobre qualidade da educação brasileira. Est. Aval. Educ., São Paulo. v. 25, n.57, p. 138-162, jan./abr. 2014.

FERNANDES, Cleudemar Alves. Análise do discurso: reflexões introdutórias. São Carlos: 2aed, Editora Claraluz, 2008.

INEP- Instituto Nacional de estudos e Pesquisas Educacionais Anísio Teixeira. Disponível em: http://portal.inep.gov.br/web/guest/pisa. Acesso em 26 de Novembro de 2018.

SANTOS, F. A. dos; VILALVA, D. M. e FERREIRA, F. da S. As implicações das avaliações em larga escala sobre a escola e o trabalho pedagógico. In: LIBÂNEO, José Carlos e FREITAS, Raquel A. Marra da Madeira Políticas educacionais neoliberais e escola pública: uma qualidade restrita de educação escolar. Editora espaço acadêmico: Goiânia, 2018.

PÊCHEUX, M. O Discurso: estrutura ou acontecimento. Trad. Eni P. Orlandi. $3^{a}$ edição - Campinas: Ed. Pontes, 2002.

PÊCHEUX, M. e GADET, F. A Língua Inatingível. Campinas: Pontes, 2004.

OCDE- Organização para a cooperação e desenvolvimento económico. Disponível em: http://http://www.oecd.org/pisa/ Acesso em 05 de Dezembro de 2018. 